\title{
Size-Controlled Si Nanocrystals for Photonic and Electronic Applications
}

\author{
M. Zacharias, L.X. Yi, J. Heitmann, R. Scholz, M. Reiche, and U. Gösele \\ Max Planck Institute of Microstructure Physics, Weinberg 2, 06120 Halle, Germany
}

Keywords: Si Nanocrystals, size control, photoluminescence, quantum confinement

\begin{abstract}
A new approach for the fabrication of ordered Si quantum dots fully compatible with normal $\mathrm{Si}$ technology is presented. The preparation of $\mathrm{SiO} / \mathrm{SiO}_{2}$ superlattices represents a simple and efficient method for fabricating highly luminescent $\mathrm{Si}$ nanocrystals and allows independent control of size, size distribution, and density. The Si nanocrystals can be arranged to a specific depth and for a specific number of layers with a nanometer adjustment. The density of the Si nanocrystals is in the range of $10^{19} / \mathrm{cm}^{3}$. TEM and XRD investigations confirm control of the upper limit of the nanocrystal size to an average size of below $2.5 \mathrm{~nm}$ with a full width at half maximum of $0.6 \mathrm{~nm}$. We report on TEM images showing early states of phase separation in $\mathrm{SiO} / \mathrm{SiO}_{2}$ superlattices and combine these results with IR and PL investigations. Three different states of phase separation are distinguished and correlated to specific luminescence and infrared features. Photoluminescence experiments after crystallization show a size-dependent blue shift of the luminescence from 950 to $750 \mathrm{~nm}$ and a luminescence intensity comparable to porous Si. The nearly size-independent PL intensity observed in our $\mathrm{SiO} / \mathrm{SiO}_{2}$ superlattices indicates the achievement of independent control of crystal size and number. In addition, $\mathrm{PECVD}$ preparation of amorphous $\mathrm{SiO} / \mathrm{SiO}_{2}$ superlattices is reported which shows a similar size dependent luminescence after crystallization.
\end{abstract}

\section{Introduction}

Bulk crystalline silicon is the standard material for semiconductor processing and devices. Due to the indirect nature of the silicon band gap, light emission of bulk crystalline silicon is highly inefficient. Hence, today's light emitting devices are normally based on III-V semiconductors. The first reports on efficient visible light emission from a silicon based material [1,2] established a period of intense research on the preparation and stabilization of porous silicon with deeper insight into the physics and chemistry of porous and nanocrystalline materials. In recent years, silicon nanocrystal research has shifted to the preparation of nanocrystals embedded in an oxide host. Methods applied for preparation are; $\mathrm{Si}$ ion implantation into high quality oxides, sputtering of $\mathrm{Si}$ rich oxides or reactive evaporation of $\mathrm{Si}$ rich oxides. With these methods the Si crystal size is controlled by the $\mathrm{Si}$ content in the $\mathrm{SiO}_{2}$ matrix and the crystal density cannot be controlled independently. In addition, there is only limited control of size distribution using these methods. During recent years, methods have been developed, based on laser pyrolysis of silan, which lead to a molecular beam of freely propagating nanoparticles [3]. Size selection was achieved by using a simple molecular beam chopper and the deposition of nanoparticles on planar substrates [4]. We recently developed a new approach for the fabrication of ordered Si nanocrystals [5]. This approach is based on the preparation of amorphous $\mathrm{SiO} / \mathrm{SiO}_{2}$ superlattices and thermal annealing for phase separation and crystallization. The preparation of $\mathrm{SiO} / \mathrm{SiO}_{2}$ superlattices is an elegant and efficient method for the synthesis of size controlled Si nanocrystal. The resulting Si nanocrystals show a strong room temperature luminescence after crystallization. The process of phase separation and crystallization of such ultra thin $\mathrm{SiO}$ layers was investigated in detail. The thermally induced phase separation was studied using a combination of IR and photoluminescence (PL) spectroscopy, and TEM investigations at selected temperatures. In addition, preliminary results will be shown for preparing the superlattice structure by plasma enhanced chemical vapor deposition (PECVD). 


\section{Experimental Details}

Amorphous $\mathrm{SiO}_{\mathrm{x}} / \mathrm{SiO}_{2}$ superlattices were prepared by reactive evaporation of $\mathrm{SiO}$ powders in an oxygen atmosphere under vacuum. The films were deposited on 4" n-type Si wafers in a conventional evaporation system with two symmetrically arranged evaporators. Rotation of the substrate enables a homogeneity of around $10 \%$ over the whole wafer. Before evaporation the chamber was pumped down to $1 \times 10^{-7}$ mbar. The substrate temperature was held constant at $100^{\circ} \mathrm{C}$. A stoichiometry of $\mathrm{x} \sim 1$ was used for the ultra thin $\mathrm{SiO}_{\mathrm{x}}$ layers. We prepared $\mathrm{SiO}$ layers with thicknesses in the range between $1 \mathrm{~nm}$ and $4 \mathrm{~nm}$ with 3 to 45 periods separated by $\mathrm{SiO}_{2}$ layers of 3 or $4 \mathrm{~nm}$. The superlattice structure forces the nanocrystals into a dense and layered arrangement. For comparison, bulk $\mathrm{SiO}$ and $\mathrm{SiO}_{2}$ films were prepared under the same conditions. In addition, amorphous $\mathrm{SiO}_{\mathrm{x}} / \mathrm{SiO}_{2}$ superlattices with 30 periods were deposited by plasma enhanced chemical vapor deposition (PECVD) at $350^{\circ} \mathrm{C}$ using $\mathrm{N}_{2} \mathrm{O}$ as oxygen source and either a $\mathrm{SiH}_{4} / \mathrm{N}_{2}$ or a SiH $4 / \mathrm{Ar}$ plasma with a RF power of $40 \mathrm{~W}$. The PECVD process enables a cost effective production of such nanocrystalline structures. Pieces of the different samples were annealed at selected temperatures between 300 and $1100^{\circ} \mathrm{C}$ for $1 \mathrm{~h}$ in nitrogen (99.999\% purity), each piece being annealed only once.

Infrared absorption (IR), photoluminescence (PL) spectroscopy and transmission electron microscopy (TEM) were used to study the phase separation and to monitor the different states of phase separation and crystallization. Infrared spectroscopy was performed using an FTIR Bruker IFS66v spectrometer equipped with a mercury cadmium telluride infrared detector in the range of 600 to $1500 \mathrm{~cm}^{-1}$ and using a plain piece of the same wafer as reference. The photoluminescence was excited by the $325 \mathrm{~nm}$ line of a HeCd laser with a power of $1.9 \mathrm{~mW}$ or $0.19 \mathrm{~mW}$. The PL signal was focused into a single monochromator and detected by a nitrogen cooled CCD camera. All spectra were corrected for spectral response of the measurement system.

Selected samples were prepared for cross section transmission electron microscopy (TEM) investigations in the usual way including final ion milling. Imaging the superlattice structures as deposited and after annealing was realized applying the Fresnel defocus method at medium magnifications. In addition, we used dark field images for showing the presence, size and size distribution of the nanocrystals. Please note, that only nanocrystals having the right orientation to the incident electron beam can be seen in the dark field contrast images. Also, the images contain contributions from nanocrystals arranged up to a depth of $40 \mathrm{~nm}$ which superimpose their signals.

\section{Experimental Results}

Amorphous $\mathrm{SiO}$ is not a stable chemical compound and will easily decompose into $\mathrm{Si}$ and $\mathrm{SiO}_{2}$ during high temperature annealing. Annealing the amorphous $\mathrm{SiO} / \mathrm{SiO}_{2}$ superlattice films at high temperatures $\left(1100^{\circ} \mathrm{C}\right)$ results in phase separation of the ultra thin $\mathrm{SiO}$ layers and in nanometer sized $\mathrm{Si}$ clusters covered by amorphous $\mathrm{SiO}_{2}$. This process is schematically shown in Fig. 1. The $\mathrm{SiO}$ layer is thermally decomposed following equation (1):

$$
\mathrm{SiO}_{x} \rightarrow \frac{x}{2} \mathrm{SiO}_{2}+\left(1-\frac{x}{2}\right) \mathrm{Si} \quad \text { with } x \sim 1
$$

Such a phase separation of the $\mathrm{SiO}$ automatically ensures that nucleated $\mathrm{Si}$ nanocrystals/nanoclusters are separated from each others by a $\mathrm{SiO}_{2}$ shell. Based on the above equation the thickness of the oxide between the Si nanoclusters depends on the stoichiometry of the $\mathrm{SiO}_{\mathrm{x}}$ as well. A cross sectional transmission microscopy (TEM) image of an actual sample after crystallization at $1100^{\circ} \mathrm{C}$ is shown in Fig. 2 and agrees well with our schematic model (Fig.1). The dark spots are the more dense Si material and represent the nanocrystals. However, the cross section 
sample has a certain thickness and contains not only one row of nanocrystals. The crystals from different depth can not be separated which effects shape and density of crystals seen in the image.

as prepared $\longrightarrow$ phase separation \& crystallization
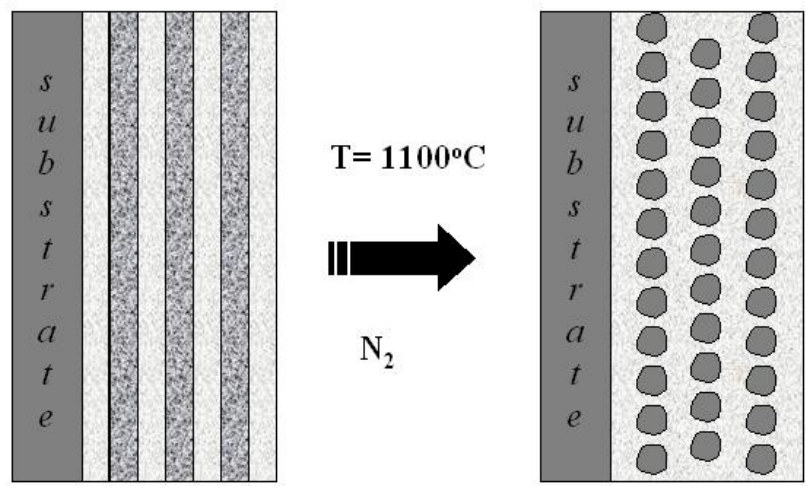

Si nanocrystal

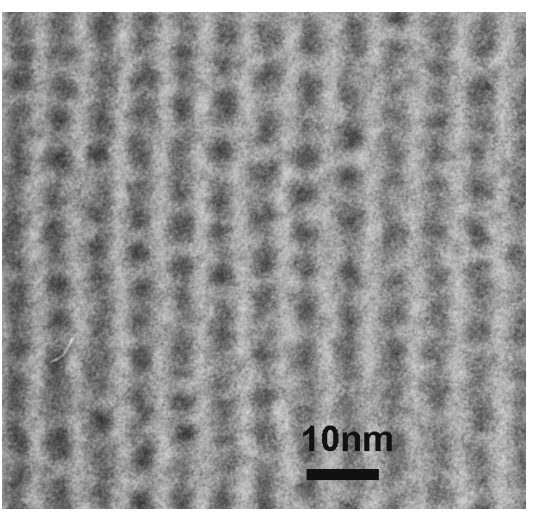

Fig. 2: Cross sectional TEM image of layer arranged $\mathrm{Si}$ crystals $(\sim 3 \mathrm{~nm})$ clearly separated by oxide.[6]

Fig. 1: Fabrication of amorphous $\mathrm{SiO} / \mathrm{SiO}_{2}$ superlattice and thermal induced phase separation and crystallization. [6]

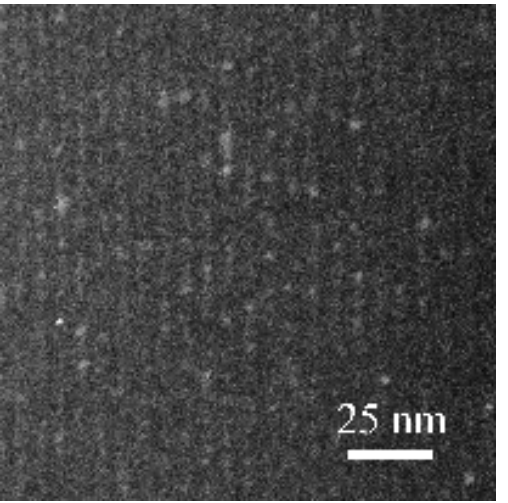

Fig. 3 (a): Dark field image of a crystallized $\mathrm{SiO} / \mathrm{SiO}_{2}$ superlattice with layer thickness of $2 \mathrm{~nm} / 3 \mathrm{~nm}$.

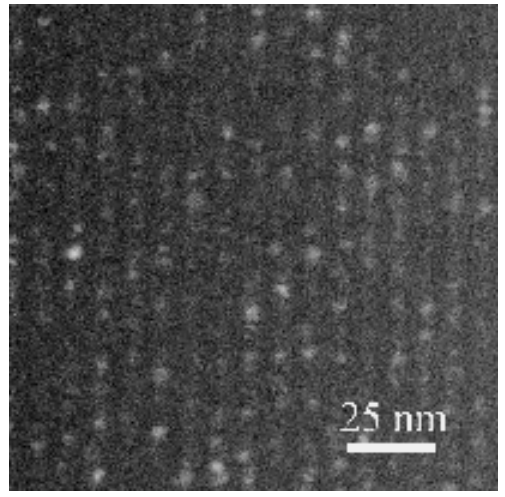

Fig. 3 (b): Dark field image of a crystallized $\mathrm{SiO} / \mathrm{SiO}_{2}$ superlattice with layer thickness of $4 \mathrm{~nm} / 3 \mathrm{~nm}$.

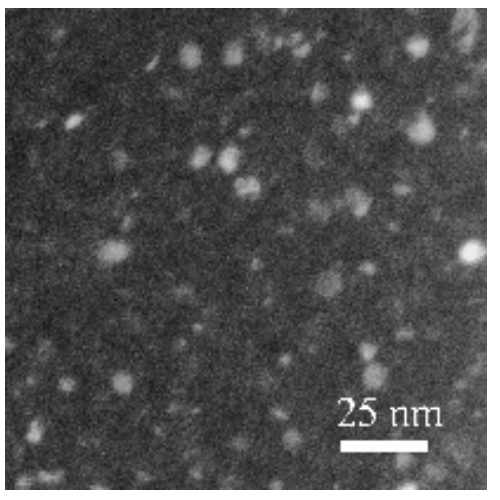

Fig. 3 (c): Dark field image of a "bulk" $\mathrm{SiO}$ film after crystallization.

Figure 3 shows the phase separation in the case of confined geometries in dark field contrast for a $2 \mathrm{~nm} / 3 \mathrm{~nm}$ (a) and a $4 \mathrm{~nm} / 3 \mathrm{~nm}$ crystallized $\mathrm{SiO} / \mathrm{SiO}_{2}$ superlattice (b). Please note, that the thicknesses given here for the as-prepared samples are nominal thicknesses estimated from the growth rate of a bulk $100 \mathrm{~nm} \mathrm{SiO}$ layer and scaled down to thin layers. In contrast, a "bulk" thick SiO film is shown in Fig. 3 (c) in dark field. The bulk SiO film shows much larger sizes and a broader size distribution of the crystals than the superlattices. Analyzing the average size and the size distribution we estimated $(4.5 \pm 1.7) \mathrm{nm}$ for the average size of the bulk SiO sample. In case of the superlattices, the thin oxide barrier separates the thin $\mathrm{SiO}$ layers and prevents interlayer diffusion during crystallization. This easily correlates the lateral size to the layer thickness for thickness below $5 \mathrm{~nm}$ and the crystallization procedure used. We found $(2.8 \pm 0.3) \mathrm{nm}$ and $(3.3 \pm 0.5) \mathrm{nm}$ for the average size of the samples in Fig. 3 (a) and (b), respectively. 
Annealing experiments using the superlattices prepared by reactive evaporation were performed to reveal the different states of phase separation by comparison of luminescence and infrared signature of different samples. The infrared spectra at temperatures ranging from $100^{\circ} \mathrm{C}$ (as-prepared) to $1100^{\circ} \mathrm{C}$ are shown in Fig. 4 for the sample with $4 \mathrm{~nm}$ thick $\mathrm{SiO}$ layers. The film with $2 \mathrm{~nm} \mathrm{SiO}$ thickness shows similar IR spectra [7]. Various silicon-oxygen related absorption bands can be seen in the range from 700 to $1500 \mathrm{~cm}^{-1}$. Due to the fact that our method is based on a totally hydrogen free process we can exclude all hydrogen related IR modes in the investigated range. The band around $810 \mathrm{~cm}^{-1}$ is assigned to $\mathrm{Si}-\mathrm{O}-\mathrm{Si}$ bond bending motion in $\mathrm{SiO}_{2}$ [8]. With higher annealing, a band at $880 \mathrm{~cm}^{-1}$ appears and increases in intensity for temperatures of $400-500^{\circ} \mathrm{C}$. The $880 \mathrm{~cm}^{-1}$ absorption loses intensity at higher temkperatures and vanishes above $700^{\circ} \mathrm{C}$. The IR vibration above $1000 \mathrm{~cm}^{-1}$ is the asymmetric stretching motion of oxygen in a Si-O-Si bridging configuration. The peak position can be used for a crude estimate of stoichiometry for homogeneous $\mathrm{SiO}_{\mathrm{x}}$ [9]. For the bulk $\mathrm{SiO}_{\mathrm{x}}$ film with $\mathrm{x} \sim 1$ a position of $980 \mathrm{~cm}^{-1}$ was measured. For the as-prepared superlattice films $\left(100^{\circ} \mathrm{C}\right)$ a position of $1039 \mathrm{~cm}^{-1}$ was found, which is the contribution of both the thin $\mathrm{SiO}$ and $\mathrm{SiO}_{2}$ layers. However, a deconvolution of the modes into the $\mathrm{SiO}$ and $\mathrm{SiO}_{2}$ parts can not be accomplished in a simple way. Due to the large number of $\mathrm{SiO}_{2}$ interfaces and the very thin layers neither the effective medium nor the Brüggeman theory is valid for our system. Hence, we only monitor the shift of the mode as a measure for the phase separation. The observed IR vibration shifts from $1039 \mathrm{~cm}^{-1}$ to $1052 \mathrm{~cm}^{-2}$ for annealing from 100 to $600^{\circ} \mathrm{C}\left(2.6 \mathrm{~cm}^{-1} / 100 \mathrm{~K}\right)$. Annealing between 700 and $900^{\circ} \mathrm{C}$ results in a more pronounced shift $\left(9.3 \mathrm{~cm}^{-1} / 100 \mathrm{~K}\right)$ with a final position at $1080 \mathrm{~cm}^{-1}$ representing the position found for the bulk amorphous $\mathrm{SiO}_{2}$ film. Further annealing at higher temperatures does not shift the peak position of the vibration mode.

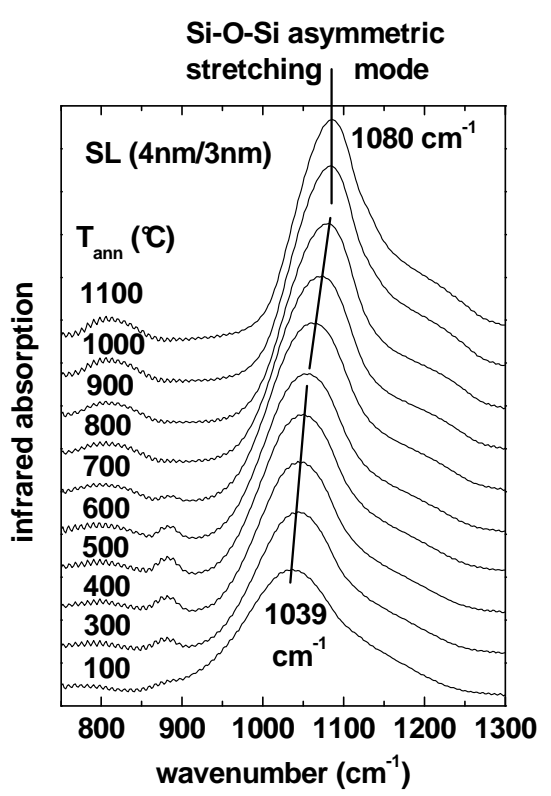

Fig. 4: IR absorption for the sample with a $4 \mathrm{~nm} / 3 \mathrm{~nm} \mathrm{SiO} / \mathrm{SiO}_{2}$ superlattice annealed at temperatures in the range between 100 and $1100^{\circ} \mathrm{C}$

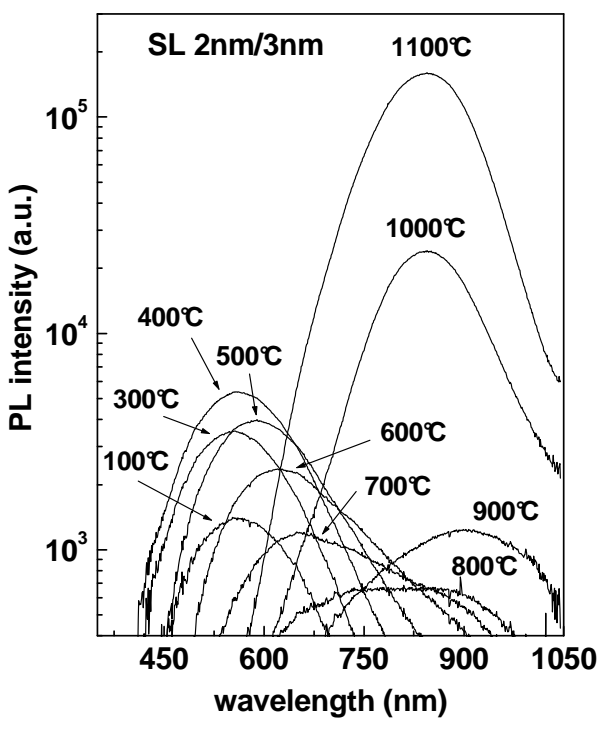

Fig. 5: Development of the PL spectra with increased annealing for the $2 \mathrm{~nm} / 3 \mathrm{~nm}$ $\mathrm{SiO} / \mathrm{SiO}_{2}$ superlattice.

Fig. 5 gives the PL spectra at different annealing stages for the sample with $2 \mathrm{~nm}$ thick SiO layers. The spectra of the sample with $4 \mathrm{~nm}$ show similar developments as a function of temperature and has already been published in [7]. Three different luminescence bands may be distinguished. A band 
at $560 \mathrm{~nm}$ is observed. The PL intensity increases first before decreasing again for higher annealing temperatures. At $800^{\circ} \mathrm{C}$ the PL band vanishes in the samples investigated so far. The PL maximum position of this band remains constant independent of the annealing temperature used.

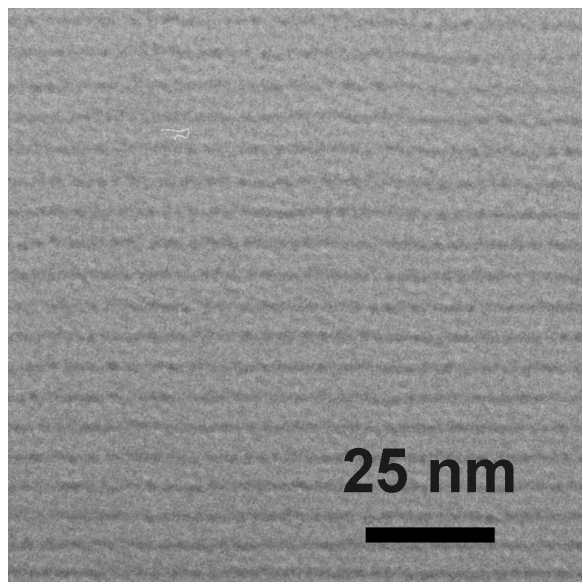

Fig. 6: TEM images of the superlattice at various states of annealing: (a) as-prepared state.

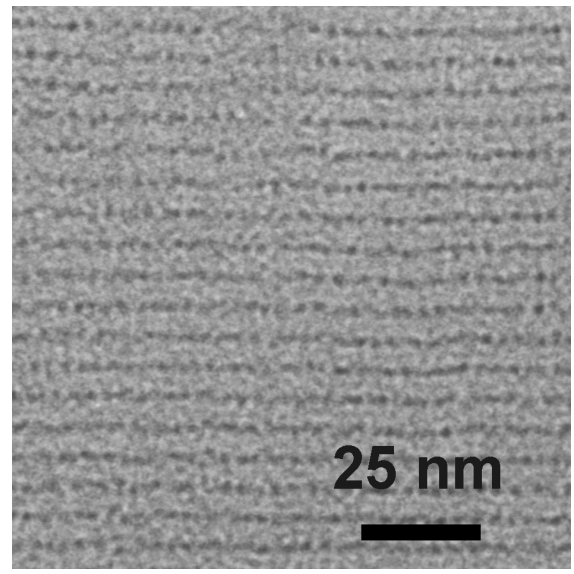

(c) after $900^{\circ} \mathrm{C}$ annealing, and

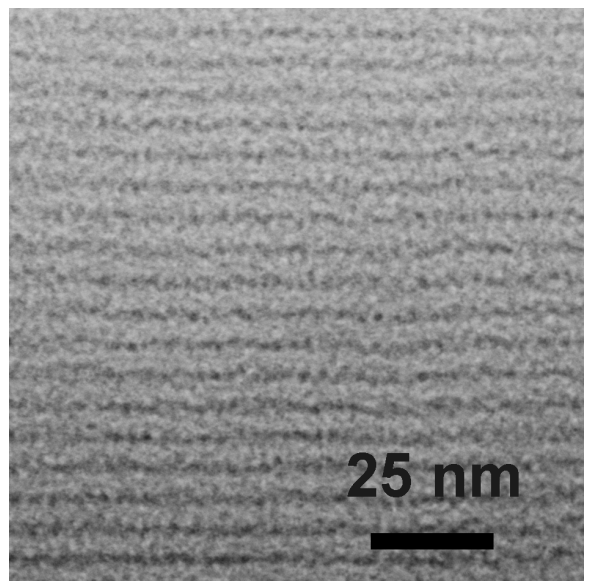

(b) after $600^{\circ} \mathrm{C}$ annealing

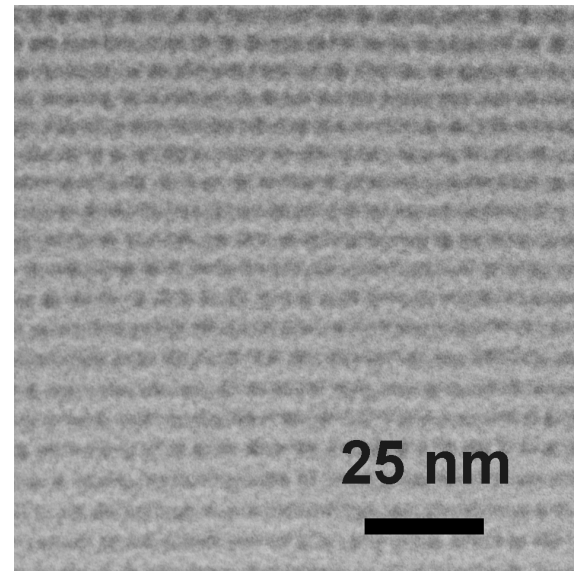

(d) after $1100^{\circ} \mathrm{C}$ annealing

At $500^{\circ} \mathrm{C}$ a second luminescence band appears which gradually shifts from a position of $750 \mathrm{~nm}$ to $880 \mathrm{~nm}$ as the annealing temperature increases from $600^{\circ} \mathrm{C}$ to $900^{\circ} \mathrm{C}$. The PL intensity of this band is weaker than that of the first luminescence band but varies from sample to sample. Finally a Gaussian shaped strong luminescence is observed for temperatures above $900^{\circ} \mathrm{C}$ with a peak position clearly depending on the $\mathrm{SiO}$ layer thickness, i.e. $800 \mathrm{~nm}$ for the sample in Fig. 5. For the sample with $4 \mathrm{~nm} \mathrm{SiO}$ layers we found a peak position of $920 \mathrm{~nm}$. The PL spectra of the whole set of samples with $\mathrm{SiO}$ layer thickness from around $4 \mathrm{~nm}$ to below $1 \mathrm{~nm}$ was shown before [5]. A size dependent blue shift from around $950 \mathrm{~nm}$ to $760 \mathrm{~nm}$ was observed with decreasing thickness without a significant drop in PL intensity. More results containing resonant excited PL spectra, lifetime and temperature dependent lifetime investigations will be presented soon [10]. As can be seen in Fig. 5, the intensity increases even more for the $1100^{\circ} \mathrm{C}$ annealing but the peak position remains constant. The PL peak intensity after crystallization is around 30 times stronger then any of the luminescence of the first and second stages. However, a significant broader non-Gaussian peak centered around $940 \mathrm{~nm}$ is observed for the bulk SiO film reflecting the larger size and the broader 
and asymmetric size distribution of the Si nanocrystals. The PL intensity of the bulk SiO film is about one order of magnitude lower compared to our superlattices.

Selected phase separation stages of the $2 / 3 \mathrm{~nm}$ film are shown in the TEM bright field images of Fig. 6 (a-d). Due to the low element contrast between the $\mathrm{SiO}$ and $\mathrm{SiO}_{2}$ layers the use of the defocus Fresnel contrast method is essential for imaging our samples. The film is amorphous for temperatures between $100^{\circ} \mathrm{C}$ (a) and $900^{\circ} \mathrm{C}$ (c), and clearly crystallized after $1100^{\circ} \mathrm{C}$ annealing (d). Especially in the case of the amorphous state of our samples, the images are strongly influenced by the Fresnel defocus contrast. In Fig. 7 we give the TEM images of an as-prepared (a) and annealed (b) PECVD sample. A phase separation similar to the evaporated superlattices is observed. The average size of the nanocrystals in Fig. 7 (b) was estimated as $(3.25 \pm 0.45) \mathrm{nm}$ for an initial $\mathrm{SiO}$ layer thickness of $3.5 \mathrm{~nm}$. Fig. 8 shows the comparison of the annealed samples with 3.5 and $3.8 \mathrm{~nm}$ layer thickness. Please note that our two PECVD prepared samples show a similar blue shift (from 958 to $894 \mathrm{~nm}$ corresponding to the used range of layer thickness) like the evaporated superlattices with comparable $\mathrm{SiO}$ layer thicknesses as can be seen in Fig. 8. The PL signal of the PECVD samples is around 20 times weaker compared to samples prepared by the evaporation technique.

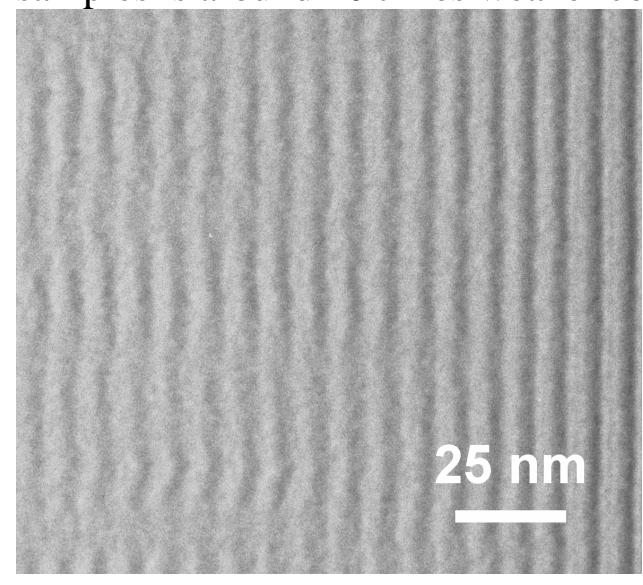

Fig. 7 (a): As-prepared $\mathrm{SiO}_{\mathrm{x}} / \mathrm{SiO}_{2}$ superlattice $(3.5 / 3.8 \mathrm{~nm})$ prepared by PECVD.

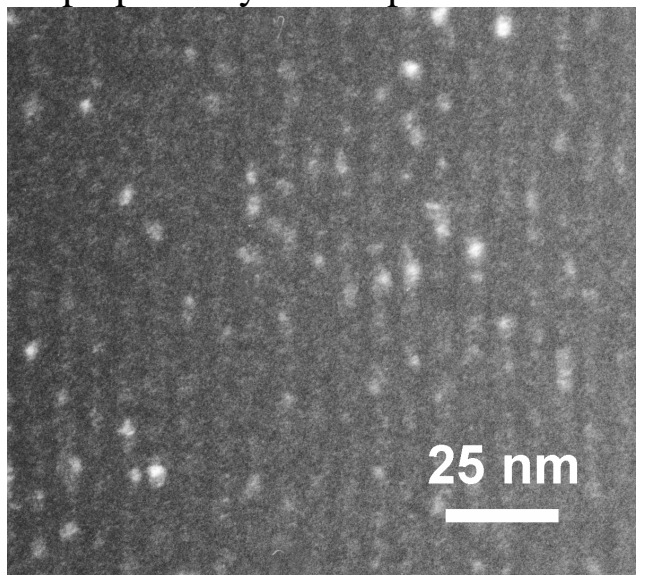

Fig. 7 (b): The same film after $1100^{\circ} \mathrm{C}$ annealing shows layered arranged $\mathrm{Si}$ nanocrystals in the dark field TEM image separated by $\mathrm{SiO}_{2}$.

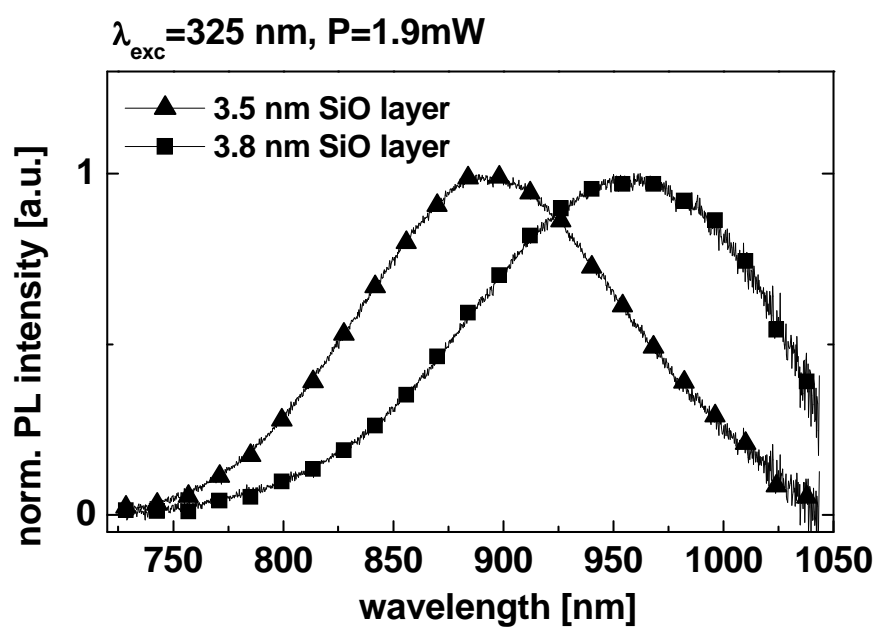

Fig. 8: PL spectra of two superlattices prepared by PECVD with $\mathrm{SiO}$ layers of 3.5 and $3.8 \mathrm{~nm}$. 


\section{Discussion}

As evident from Fig. 1 to 3, well arranged Si nanocrystals can be fabricated with a narrow size distribution. The thickness of the $\mathrm{SiO}$ layer limits the crystallization process and determines the size of the approximately spherical nanocrystals. Larger crystals can clearly be avoided by using our special superlattice structure. The density of crystals is increased in the superlattice approach as compared to the crystallized bulk $\mathrm{SiO}$ film and is in the range of $10^{19} \mathrm{~cm}^{-3}$. This fact is very important for high PL intensities because the intensity scales directly with the number of excited nanocrystals. Larger crystals might contain defects, i.e. the carriers might preferably recombine using non-radiative channels. Also, the lifetime is longer and the recombination probability is lower for larger nanocrystals [10].

Our combined IR absorption and PL experiments were focused to demonstrate the evidence of early stages of phase separation and how, in principle, the phase separation takes place in the limit of ultra thin layers strained by $\mathrm{SiO}_{2}$ interfaces. We conclude from our IR experiments that the phase separation process of the annealed $\mathrm{SiO} / \mathrm{SiO}_{2}$ superlattice can be divided into three stages:

- Stage 1 for annealing temperatures up to $600{ }^{\circ} \mathrm{C}$ is characterized by a PL signal at $560 \mathrm{~nm}$ and a corresponding $880 \mathrm{~cm}^{-1}$ IR absorption.

- Stage 2 for annealing temperatures between $600^{\circ} \mathrm{C}$ and $900^{\circ} \mathrm{C}$ still represents an amorphous state of the superlattice. Stage 2 is characterized by a more pronounced IR shift of the Si-OSi bridging mode above $1000 \mathrm{~cm}^{-1}$, the vanishing of the PL at $560 \mathrm{~nm}$ and the development of a new PL band which gradually shifts its position to $900 \mathrm{~nm}$ with increasing temperature.

- Stage 3 is observed for annealing temperatures above $900^{\circ} \mathrm{C}$. It is associated with a very strong red or near infrared luminescence with the peak position depending on the $\mathrm{SiO}$ layer thickness, no further changes in the Si-O related absorption band, and $\mathrm{Si}$ nanocrystals are detected in the former $\mathrm{SiO}$ layer.

Stage 1 can be understood as a first rearranging and ordering of bond angles and bond length in the amorphous material without a significant phase separation. The $880 \mathrm{~cm}^{-1}$ absorption mode has been discussed in literature either as a mode related to oxide isolated Si rings [11,12,13] or as a bending motion of pyramidal oxygen complex \{14]. The mode is exclusively observed in the temperature range where reordering takes place and is obviously a signature of such processes. The reconstruction, ordering and phase separation is accompanied by diffusion of $\mathrm{Si}, \mathrm{O}$ atoms or $\mathrm{Si}-\mathrm{O}$ groups. Having no hydrogen at all in the films the $880 \mathrm{~cm}^{-1}$ band is clearly assigned to oxygen. The $\mathrm{O}_{3}$ pyramidal configuration discussed in [14]with one oxygen bonded to three silicon atoms seems energetically rather unlikely even for oxygen at the surface of very small Si clusters. Oxide isolated $\mathrm{Si}$ rings represent a plane arrangement of the basic lattice cells for the developing Si clusters and $\mathrm{Si}$ nanocrystals. It is not clear to date if there are special groups favoured which mediate the phase separation and diffusion process in the amorphous $\mathrm{SiO}$ and show up in IR. Thus, additional experiments and calculations are needed for unambiguous assignment of the $880 \mathrm{~cm}^{-1}$ mode.

Bond structures occur in the matrix during the annealing which represent different types of defects as intermediate states. The increase and decrease of the defect related PL at $560 \mathrm{~nm}$ with temperature is at least a hint for such states. The $560 \mathrm{~nm}$ PL found various explanations in literature. Similar to our PL, Ghislotti [15] and Rinnert et al. [16] reported an increasing number of radiative defects produced by ion implantation. According to Liao et al.[17], the defect is the E' center $\left(\mathrm{O}_{3} \equiv \mathrm{Si} \bullet\right)$ and it is reported that the defect density decreases with thermal annealing and is almost undetectable at $1000^{\circ} \mathrm{C}$. In contrast, Jeong et al. [18] assumed that the E' center does not contribute 
to radiative recombination and suggested that the orange luminescence presumably originates from other defects such as the non-bridging oxygen hole center ( $\mathrm{NBOHC}, \mathrm{O}_{3} \equiv \mathrm{Si}-\mathrm{O} \bullet$ ) [19]. Also, a decrease of the $560 \mathrm{~nm}$ PL intensity and a corresponding decrease of the $880 \mathrm{~cm}^{-1} \mathrm{IR}$ absorption is observed in this report above annealing temperatures of $500^{\circ} \mathrm{C}$.

In our three stage model, we expect a growth of the planar Si rings into 3 dimensional amorphous $\mathrm{Si}$ clusters for higher annealing temperatures. At the cluster surface, different bond defects will remain up to completing the phase separation. Although similar IR and PL bands have been reported for siloxen [20,21], we exclude siloxen structures in our superlattice. Our structures do not contain any hydrogen due to the high vacuum evaporation of $\mathrm{SiO}$ powder and inert gas $\left(\mathrm{N}_{2}\right)$ annealing process used. Using IR spectroscopy we did not see any hydrogen-related wagging or stretching modes.

The appearance of amorphous Si nanoclusters in the TEM image for annealing temperatures above $600^{\circ} \mathrm{C}$ corresponds to the appearance of the second PL band in stage 2. Similar PL spectra for amorphous $\mathrm{Si} / \mathrm{SiO}_{2}$ superlattices prepared by rf magnetron reactive sputtering from a silicon target in argon gas were reported by Liu et al. \{22] Furukawa et al. [23] observed the process of Si cluster formation in $\mathrm{SiO}_{2}$ films for annealing between 750 and $950^{\circ} \mathrm{C}$. Kanzawa et al. [24] prepared samples by RF co-sputtering of $\mathrm{Si}$ and $\mathrm{SiO}_{2}$ which showed a broad PL band in the visible region (1.6-1.9 eV) and a red shift with increasing annealing temperature and Si concentration. In our samples, we see the development of amorphous clusters and an increase of the amorphous cluster size in TEM (Fig. 6) between $600^{\circ} \mathrm{C}$ and $900^{\circ} \mathrm{C}$ which agrees with the observed red shift of the PL. For amorphous clusters the PL signal is expected to be very weak which is in agreement with our observations.

The phase separation of the amorphous $\mathrm{Si}$ and $\mathrm{SiO}_{2}$ phase is completed at $900^{\circ} \mathrm{C}$ as evident from the now stable $1080 \mathrm{~cm}^{-1} \mathrm{IR}$ absorption for the higher annealing temperature (Fig. 4). Above $900^{\circ} \mathrm{C}$ the crystallization of the amorphous Si clusters into Si nanocrystals takes place limited by the former $\mathrm{SiO}$ layer thickness. The Si nanocrystals then can be seen in the dark field TEM images as bright spots. The fixed position of the PL above $900^{\circ} \mathrm{C}$ shows that the size of the Si nanocrystals is determined by the former thickness of the $\mathrm{SiO}$ layer and the correlated cluster size. However, after $1000^{\circ} \mathrm{C}$ not all of the $\mathrm{Si}$ clusters are crystallized which results in a lower PL intensity. By using $1100^{\circ} \mathrm{C}$, more and more clusters are crystallized. This can be explained by the exponential dependence of the crystallization temperature from cluster size [25]. Smaller crystals need a higher temperature for crystallization which is reflected by the strongly enhanced PL intensity for the $2 \mathrm{~nm}$ $\mathrm{SiO}$ layer sample after $1100^{\circ} \mathrm{C}$. The quantum confinement origin for the strong room temperature luminescence has been discussed in detail elsewhere $[5,10]$

The superlattice approach was tested by using PECVD which is demonstrated in Fig. 7 (a,b) but needs further optimization. The as-prepared samples show a slightly wavy structure which is the result of an unoptimized process. Nevertheless, for such films, the size of the nanocrystals can be controlled as demonstrated by the PL blue shift for thinner SiO layer thicknesses. This opens the way for mass production of such structures in a very cost efficient way. All the samples show room temperature PL. However, in our first experiments, the PL intensity was significantly lower than with the evaporated samples. The lower PL intensity might be due to a lower number of $\mathrm{Si}$ nanocrystals in the films. Also, the films were deposited using a hydrogen and nitrogen containing gas. We expect a significant influence of hydrogen within the films on the phase separation process and the remaining defects in the films. It is known that hydrogen effuses at $\sim 500^{\circ} \mathrm{C}$ for amorphous silicon. We expect a strong influence on the early states of phase separation because a large amount of hydrogen saturates the bonds necessary for an efficient rearrangement of the oxygen atoms during 
the phase separation process. No further investigations and parameter optimization of the PECVD films and the annealing process have been performed so far. Nevertheless, the presented preliminary data demonstrate that PECVD has the potential to be used for preparing high-density size-controlled Si nanocrystals. Further investigations will be carried out in the near future.

\section{Summary}

We can arrange Si nanocrystals to a specific depth and for a specific number of layers and with a specific density. The thickness of the $\mathrm{SiO}$ layer controls the size of the crystals. The stoichiometry parameter $\mathrm{x}$ enables the control of the crystal density within the layers as well as the separation of the nanocrystals by a sufficiently thick oxide barrier. The density of the Si nanocrystals is in the range of $10^{19} / \mathrm{cm}^{3}$. Using our three stage model we developed a more comprehensive understanding of phase separation and crystallization showing that the different and seemingly contradicting observations in the literature can be understood as different stages of network reorganization. The amorphous state of the $\mathrm{SiO}$ layer can be understood as a mixture of $\mathrm{Si}$ rings isolated by oxide as nucleation sites for small $\mathrm{Si}$ clusters in the temperature range between $100^{\circ} \mathrm{C}$ and $600^{\circ} \mathrm{C}$. Amorphous $\mathrm{Si}$ clusters are growing between $600^{\circ} \mathrm{C}$ and $900^{\circ} \mathrm{C}$ and the crystallization of these amorphous $\mathrm{Si}$ clusters takes place above $900^{\circ} \mathrm{C}$. The size of the resulting $\mathrm{Si}$ nanocrystals is predetermined by the $\mathrm{SiO}$ layer thickness and the corresponding cluster size. Si rings, amorphous $\mathrm{Si}$ clusters and $\mathrm{Si}$ nanocrystals are correlated to different states of a non-stoichiometric $\mathrm{SiO}_{\mathrm{x}}$ matrix having typical signatures in IR absorption and photoluminescence. Photoluminescence experiments show a size-dependent blue shift of the luminescence due to quantum confinement. We demonstrated the possibility of PECVD for the preparation of size controlled Si nanocrystals.

\section{Acknowledgement}

The authors acknowledge Oxford Instruments for help in preparation of the PECVD samples. Financial support by the DFG are grateful acknowledged.

\section{References}

[1] L. Canham, Appl. Phys. Lett. 57 (1990), 1046.

[2] L. V. Lehmann, U. Gösele, Appl. Phys. Lett. 58 (1991), 856.

[3] G. Ledoux, J. Gong, F. Huisken, O. Guillois and C. Reynaud, Appl. Phys. Lett. 80 (2002), 4834.

[4] M. Ehbrecht, F. Huisken, Phys. Rev. B 59 (1999), 2975.

[5] M. Zacharias, J. Heitmann, R. Scholz, M. Schmidt, Appl. Phys. Lett. 80 ( 2002), 661.

[6] M. Zacharias, J. Heitmann, U. Gösele, MRS Bulletin 26 (2001), 975.

[7] L.X. Yi, J. Heitmann, R. Scholz, M. Zacharias, Appl. Phys. Lett., in press.

[8] D. V. Tsu, G. Lucovsky, B. N. Davidson, Phys. Rev. B 40 (1989), 1795.

[9] F. Stolze, M. Zacharias, S. Schippel, B. Garke, Solid State Commun. 87 (1993), 805.

[10] J. Heitmann, D. Kovalev, M. Zacharias, submitted.[

11] M. Zacharias, D. Dimova- Malinovska, M. Stutzmann, Phil. Mag. B 73 (1996), 799.

[12] H. Kriegsmann, Z. Anorg. Allg. Chem. 298 (1959), 232.

[13] V. Belot, R. J. P. Corriu, D. Leclercq, P. Lefevre, P. H. Mutin, A. Vioux, A. M. Flank, J. Non-crystalline Solids 127 (1991), 207.

[14] S.Y. Lin, J. Non-Crystalline Solids 266 (2000), 850.

[15] G. Ghislotti, B.Nielsen, P. Asoka-Kumar, K. G. Lynn, L. F. Di Mauro, C.E. Bottani,

F. Corni, R.Tonini, G.P. Ottaviani, J. Electrochem. Soc. 144 (1997), 2196.

[16] H. Rinnert, M. Vergnat, G. Marchal, A. Burneau, J. Lumin. 80 (1999), 445. 
[17] L. S. Liao, X. M. Bao, N. S. Li, X. Q. Zheng, N. B. Min, J. Lumin. 68 (1996), 199.

[18] J. Y. Jeong, S. Im, M. S. Oh, H. B. Kim, K. H. Chae, C. N. Whang, J. H. Song, J. Lumin. 80 (1999), 285.

[19] F. L. Galeener, D. B. Kerwin, A. J. Miller, J. C. Mikkelsen, Solid State Commun. 82 (1992), 271.

[20] U. Dettlaff-Weglikowska, W. Hönle, A. Molassioti-Dohms, S. Finkbeiner, J. Weber, Phys. Rev. B 56 (1997), 13132.

[21]S. L. Friedman, M. A. Marcus, D. L. Adler, Y. H. Xie, T. D. Harris, P. H. Citrin, Appl. Phys.Lett. 62 (1993), 1934.

[22] N. N. Liu, J. M. Sun, S. H. Pan, Z. H. Chen, R. P. Wang, W. S. Shi, X. G. Wang, Superlattices and Microstructure 28 (2000), 157.

[23] K. Furukawa, Y. Liu, H. Nakashima, D. Gao, K. Uchino, K. Muraoka, H. Tsuzuki, Appl. Phys. Lett. 72 (1998), 725.

[24] Y. Kanzawa, S. Hayashi, K. Yamamoto, J. Phys.: Condens. Matter 8 (1996), 4823.

[25] M. Zacharias, P. Streitenberger, Phys. Rev. B 62 